\title{
Synthesis and Initial Pharmacology of Heterobivalent Ligands Targeting Putative Complexes of Integrin $\alpha$ V $\beta 3$ and PAR2
}

\author{
Mark W. Majewski, ${ }^{\dagger}$ Disha M. Gandhi, ${ }^{\dagger}$ Trudy Holyst,‡ Zhengli Wang, ${ }^{\ddagger}$ Irene Hernandez, ${ }^{\ddagger}$ Ricardo \\ Rosas, Jr., ${ }^{\dagger}$ Saravanan Subramaniam, ${ }^{\ddagger}$ Jieqing Zhu, ${ }^{\ddagger, \Delta}$ Hartmut Weiler,,$₫ \S$ and Chris Dockendorff*,, \\ ${ }^{\dagger}$ Department of Chemistry, Marquette University, P.O. Box 1881, Milwaukee, WI, 53201-1881, USA \\ :Blood Research Institute, Versiti, Milwaukee, WI, 53226, USA \\ $\S$ Department of Physiology, Medical College of Wisconsin, Milwaukee, WI, 53226, USA \\ ${ }^{\Delta}$ Department of Biochemistry, Medical College of Wisconsin, Milwaukee, WI, 53226, USA
}

\section{KEYWORDS: Protease-Activated Receptor, PAR2, integrin, $\alpha$ VB3, bivalent ligand}

\begin{abstract}
Unpublished data from our labs led us to hypothesize that activated Protein C (aPC) may initiate an antiinflammatory signal in endothelial cells by modulating both the integrin $\alpha \mathrm{V} \beta 3$ and Protease-Activated Receptor 2 (PAR2), which may exist in close proximity on the cellular surface. To test this hypothesis and to probe the possible inflammation-related pathway, we designed and synthesized heterobivalent ligands composed of modified versions of two $\alpha \mathrm{V} \beta 3$ ligands and two agonists of PAR2. These novel ligands were connected via copper-catalyzed alkyne-azide cycloadditions with polyethylene glycol (PEG) spacers of variable length. Initial in vitro pharmacology with EA.hy926 and HUVEC endothelial cells indicated that these bivalent ligands are effective binders of $\alpha \mathrm{V} \beta 3$ and potent agonists of PAR2. These bivalent ligands were also used in preliminary studies investigating their effects on PAR2 signaling in the presence of inflammatory agents, and represent the first examples of ligands targeting both PARs and integrins.
\end{abstract}

\section{INTRODUCTION}

Protease-Activated Receptors (PARs) are an important family of G-protein coupled receptors (GPCRs) that possess their own agonists: a tethered ligand at the $\mathrm{N}$-terminus that is activated upon cleavage by certain extracellular proteases. ${ }^{1}$ The subtype PAR2 has been implicated in a range of inflammatory processes, ${ }^{2}$ and PAR2 antagonists ${ }^{3}$ have been investigated in cellular and animal models of inflammation, including examples related to colitis, arthritis, obesity, and pain, ${ }^{4-6}$ as well as for cancer metastasis. ${ }^{7}$ However, PAR2 ligands have yet to reach clinical stages, and it is unclear if they can be safely utilized without adversely affecting normal PAR2 signaling in a range of tissues. One approach could involve the use of biased PAR2 ligands that may more selectively inhibit pathological signaling. ${ }^{8-11}$ The now well-established concept of biased GPCR signaling ${ }^{12-15}$ suggests that the physiologic outcomes of PAR2 activation likewise depend on the cellular context (cell type), agonist/ligand-specific mode of activation, heterodimerization with other members of the PAR fami$1 y,{ }^{16,17}$ and on the interaction of PARs with protease-specific co-receptors such as tissue factor or the endothelial cell protein $\mathrm{C}$ receptor. ${ }^{18} \mathrm{~A}$ notable example of such cell- and contextspecific PAR signaling outcomes has been described in animals subjected to experimental models of septic inflammation, where disease stage-specific protective effects of PAR1 signaling required transactivation of PAR2 on endothelial cells. ${ }^{19}$ We reasoned that tissue and/or context-selectivity for PAR2 signal modulation could be facilitated by targeting putative heteromeric complexes of PAR2, especially with increasing evidence for the existence of complexes of PARs with other PARs or alternative receptors. ${ }^{16,17}$ We hypothesize that these complexes can be targeted with heterobivalent ligands composed of scaffolds established to bind to the individual targets, connected by a suitable spacer. ${ }^{20-22}$ We recently disclosed our first efforts in this area targeting putative PAR1/PAR2 heteromers. ${ }^{23}$

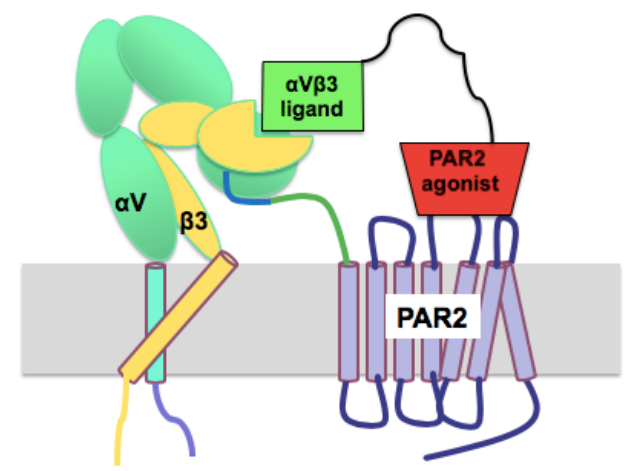

Figure 1. Design of $\alpha \mathrm{V} \beta 3-\mathrm{PAR} 2$ bivalent ligands targeted to putative receptor complexes.

Recently, preliminary studies from our labs measuring the effects of several cytotoxins on both immune and endothelial cells suggested that the integrin receptor $\alpha \mathrm{V} \beta 3$ and PAR2 may 
play synergistic roles in mediating the anti-inflammatory action of activated Protein $\mathrm{C}$ ( $\mathrm{aPC}$ ), a serine protease that is a central player in the coagulation cascade. ${ }^{24} \mathrm{aPC}$ acts as an anticoagulant by downregulating the activation of thrombin, but it has also demonstrated a range of potent antiinflammatory and cytoprotective effects, such that it was marketed for the treatment of sepsis prior to its withdrawal. ${ }^{25}$ Its effects can be mediated by both PAR1 and PAR2, among numerous targets. Under the assumption that $\alpha \mathrm{V} \beta 3$ and PAR2 may both be activated by aPC and are both in close proximity on the cell surface, we reasoned that it could be possible to selectively recapitulate the anti-inflammatory effects of aPC by targeting both $\alpha \mathrm{V} \beta 3$ and PAR2 with a heterobivalent ligand (Figure 1). Such ligands may also permit their delivery to specific cellular targets, such as $\alpha \mathrm{V} \beta 3$-expressing vascular endothelial cells. This manuscript describes the design and synthesis of the first examples of such ligands utilizing PAR2 agonists, along with our early efforts to study their effects in endothelial cells.

\section{MATERIALS AND METHODS}

The Supporting Information contains all assay protocols, synthetic protocols, and select characterization data $\left({ }^{1} \mathrm{H} \mathrm{NMR}\right.$, ${ }^{13} \mathrm{C}$ NMR, and LC-MS traces).

\section{RESULTS AND DISCUSSION}

\section{Design of Bivalent Ligands}

In order to engage each of the target receptors with a bivalent ligand, it is critical to identify scaffolds that are suitably modifiable. Ideal scaffolds should possess structure-activity relationship (SAR) data and/or structural information that indicate where an "adapter" can be added for connection to a spacer to bridge the gap between the receptors. Several scaffolds have been identified in ligands targeting either $\alpha \mathrm{V} \beta 3$ or PAR2.

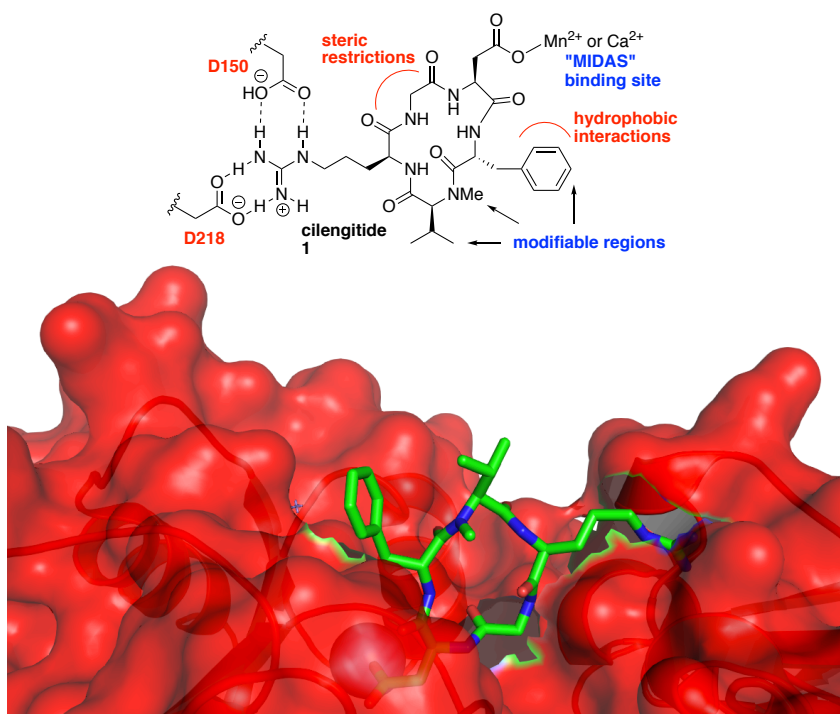

Figure 2. X-ray structure of cilengitide bound to $\alpha \mathrm{V} \beta 3 .{ }^{26}$ Solvent accessible surface is colored red, rendered using MacPyMOL v.1.8.6.

Integrins are receptors that mediate cell adhesion, and their role in blood clotting, angiogenesis, bone remodeling, and immune responses has prompted the investigation of their ligands for the prevention or treatment of thrombosis, cancer, osteoporosis, and inflammatory diseases. ${ }^{27-29}$ Many of the integrin ligands that have been developed mimic the conserved RGD binding domain of natural protein ligands such as fibronectin, fibrinogen, and vitronectin. We chose to focus on two such $\alpha \mathrm{V} \beta 3$ ligands developed by Kessler and coworkers, ${ }^{30}$ the macrocyclic RGD-containing peptide cilengitide (1, Figures 2 and 3), ${ }^{31,32}$ and the $\beta$-amido acid 2 (Figure 3 ). ${ }^{33}$ Cilengitide is notable for being the first anti-angiogenic drug candidate (which progressed to phase 2 clinical trials for glioblastoma), and $\mathbf{2}$ is noteworthy for its high potency and excellent selectivity versus $\alpha 5 \beta 1$. We also chose cilengitide for the insight provided by its X-ray structure in complex with the extracellular segment of $\alpha \mathrm{V} \beta 3$. $^{26}$
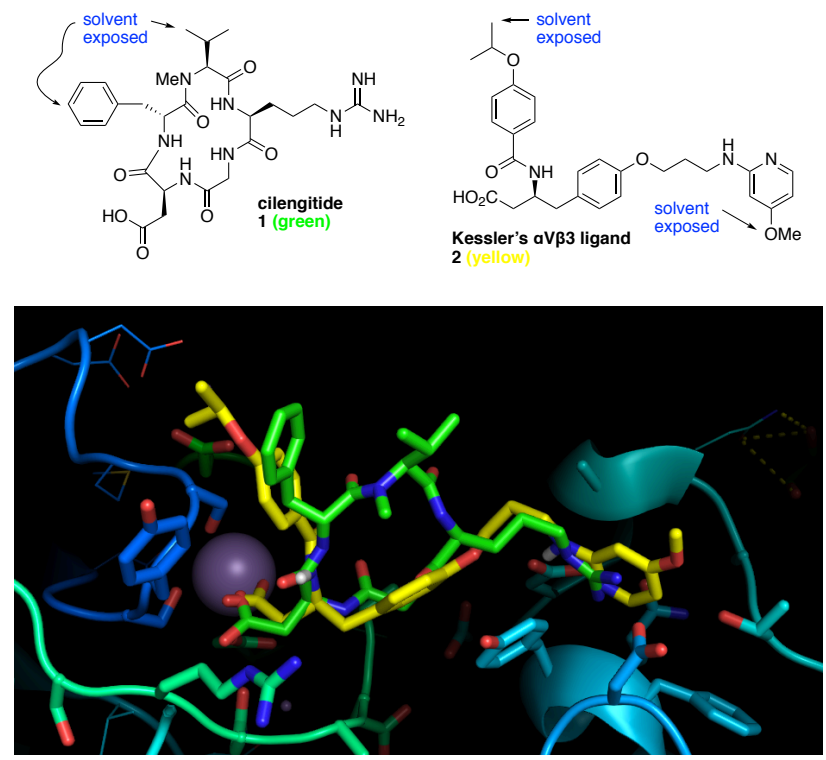

Figure 3. Docked structure of Kessler's $\alpha \mathrm{V} \beta 3$ ligand (yellow) overlaid on the X-ray structure of $\alpha \mathrm{V} \beta 3$-cilengitide (green). The manganese ion of the binding site is shown as a gray sphere. Docking was performed with FITTED ${ }^{34}$ and results visualized using MacPyMOL v.1.8.6.

Inspection of the $\alpha \mathrm{V} \beta 3$-cilengitide structure (Figure 2) showed that the valine residue of cilengitide is particularly solvent exposed, and we reasoned that this would be an ideal site for inclusion of the adapter required for spacer attachment (vide infra). Docking ${ }^{34}$ of the peptidomimetic ligand 2 to $\alpha \mathrm{V} \beta 3$ (Figure 3 ) showed the expected binding of the carboxylic acid of 2 to the manganese of the metal ion-dependent adhesion site (MIDAS), and the ligand overlaid nicely with the $\mathrm{X}$-ray structure of cilengitide bound to the same site. The isopropoxy and methoxy groups of $\mathbf{2}$ are reasonably solvent exposed and could represent suitable adapter positions for bivalent ligands. Kiessling reported a similar strategy for the design of bifunctional molecules targeting $\alpha \mathrm{V} \beta 3$ and anti- $\alpha-$ galactosyl antibodies; ${ }^{35}$ other cyclic RGD ligands connected to various tags have also been reported. ${ }^{36-44}$

The reported PAR2 agonists are variations of PAR2 tethered ligand peptides which are connected to the receptor at the $\mathrm{C}$ termini. Therefore, it stands to reason that it should be possible to attach a spacer at the C-termini of these ligands. Fatty acid (palmitoyl)-based membrane anchors have been attached to 
PAR2 agonist peptides at sites proximal to the C-termini, and these have been reported by Boitano to be highly potent PAR2 agonists, in fact up to 200-fold higher than the parent peptides. ${ }^{45}$ Very recently and subsequent to our development of the bivalent ligands reported here, researchers at AstraZeneca reported a model for the binding of the PAR2 agonist peptide SLIGKV to PAR $2,{ }^{46}$ using as a starting point the $\mathrm{x}$-ray structure of a modified version of PAR2 complexed with the antagonist AZ8838. ${ }^{47}$ These results all suggested that it should be feasible to attach a spacer to the C-termini of peptidic PAR2 agonists without losing activity to a punitive degree.

\section{Synthesis of $\alpha \mathrm{V \beta 3}$ Ligands}

We proceeded to synthesize an analog of cilengitide with the valine residue replaced by propargyl glycine to permit convenient, late stage connection to azide-containing spacers using copper-catalyzed alkyne-azide cycloadditions (CuAAC) (Scheme 1). ${ }^{48,49}$ This was prepared starting with a solid-phase peptide synthesis (SPPS) using an automated microwave peptide synthesizer, though Yamada and Shimizu report an alternative protocol optimized for cyclic RGD peptides. ${ }^{50}$ A chlorotrityl resin, preloaded with glycine, was coupled sequentially with the Fmoc-protected amino acids Pbf-arginine, ${ }^{51}$ propargyl-glycine, D-phenylalanine, and $t$-Bu-aspartate, using $\mathrm{COMU}^{\circledR}$ as the coupling reagent. ${ }^{52}$ The peptide was cleaved from the resin using acetic acid in 2,2,2-trifluoroethanol/DCM, leaving the $\mathrm{Pbf}$ and $t$-Bu protecting groups intact. The resulting linear peptide 4 was cyclized with PyBOP at $0{ }^{\circ} \mathrm{C}$ to yield the protected macrocycle $\mathbf{5}$ with alkyne adapter ready for conjugation.

\section{Scheme 1. Synthesis of alkynyl-cilengitide 5}

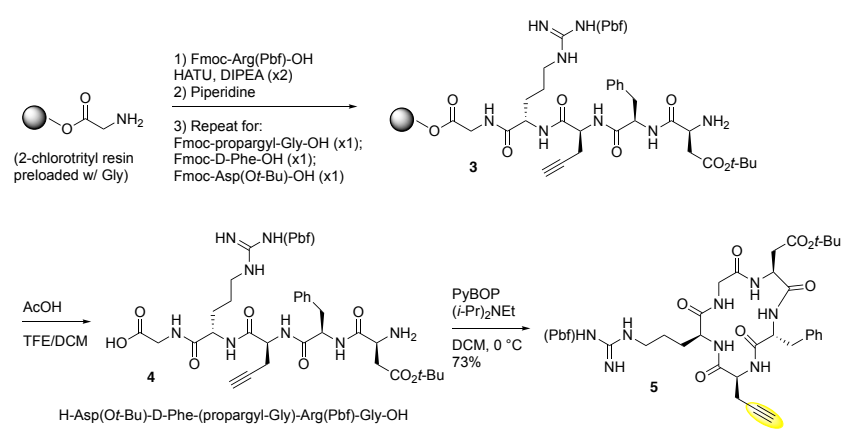

Scheme 2. Synthesis of alkynyl-modified Kessler ligand 15

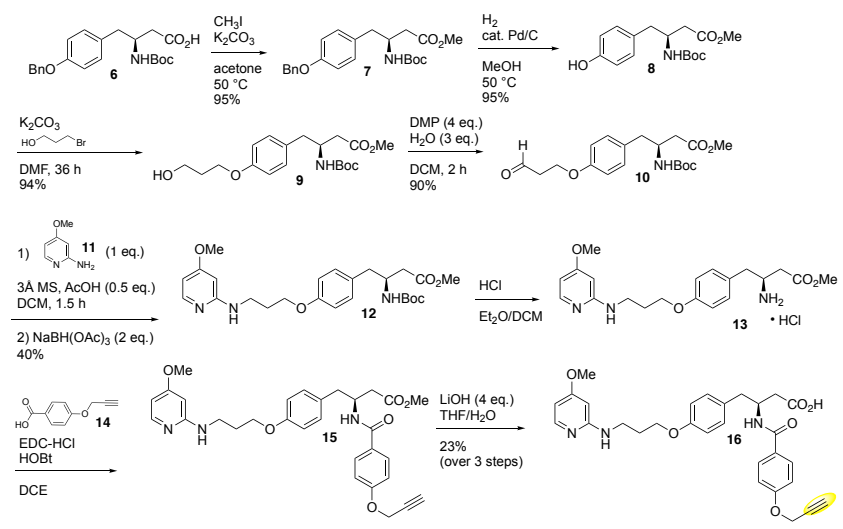

Additionally, we elected to replace the isoproxy group of the peptidomimetic $\alpha \mathrm{V} \beta 3$ ligand $\mathbf{2}$ with a suitable alkyne for connection to spacers. The commercially available protected $\beta$-amino acid 6 was converted to methyl ester 7, then the phenol was deprotected via hydrogenolysis to give phenol 8. Following Kessler's reported synthesis of $2,{ }^{33}$ this was alkylated with 3-bromo-1-pentanol to give alcohol 9, which was oxidized with Dess-Martin periodinane (DMP) (providing aldehyde 10) and subjected to a reductive amination reaction with 2-amino-4-methoxypyridine (11) to give amine 12. Removal of the Boc group with $\mathrm{HCl}$, followed by amide coupling with the benzoic acid $\mathbf{1 4}$ yielded amide $\mathbf{1 5}$, which was hydrolyzed to yield the desired acid 16, possessing a pendant alkyne.

\section{Synthesis of PAR2 Ligands}

We selected several reported PAR2 peptide agonists of varying lengths to be included in our set of bivalent ligands. It should be noted that ligands with variable PAR2 signal biases have been reported; for example, Hollenberg reported peptides that could activate intracellular calcium mobilization without activating mitogen-activated protein kinase (MAPK) in HEK (human embryonic kidney) cells, and peptides that activated both. ${ }^{8}$ More recently, Fairlie reported peptides with varying biases for PAR2-driven calcium mobilization and ERK1/2 phosphorylation. ${ }^{10}$

AY77 is a dipeptide with C-terminal amide reported by Fairlie to be a potent PAR2 agonist for calcium mobilization $\left(\mathrm{EC}_{50}=33 \mathrm{nM}\right.$ in human PAR2-expressing CHO cells). ${ }^{53} \mathrm{We}$ selected it as our smallest PAR2 agonist that may be suitable for conjugation, and with its relatively simple structure, larger quantities would be easily accessible. We synthesized it as the C-terminal acid via solution phase (Scheme 3), rather than with the solid phase protocol reported for the preparation of the C-terminal amide. The acid moiety of $N$-Boc cyclohexylglycine 17 was protected via allylation, then $\mathrm{N}$-deprotected and coupled with cyclohexylalanine $\mathbf{2 0}$ to generate the protected dipeptide 21. The Boc group was removed and the amine was coupled with isoxazole-acid $\mathbf{2 2}$, then the allyl group was removed with catalytic palladium to yield the desired acid 24a.

\section{Scheme 3. Synthesis of the acid derivative of the PAR2 agonist AY77}
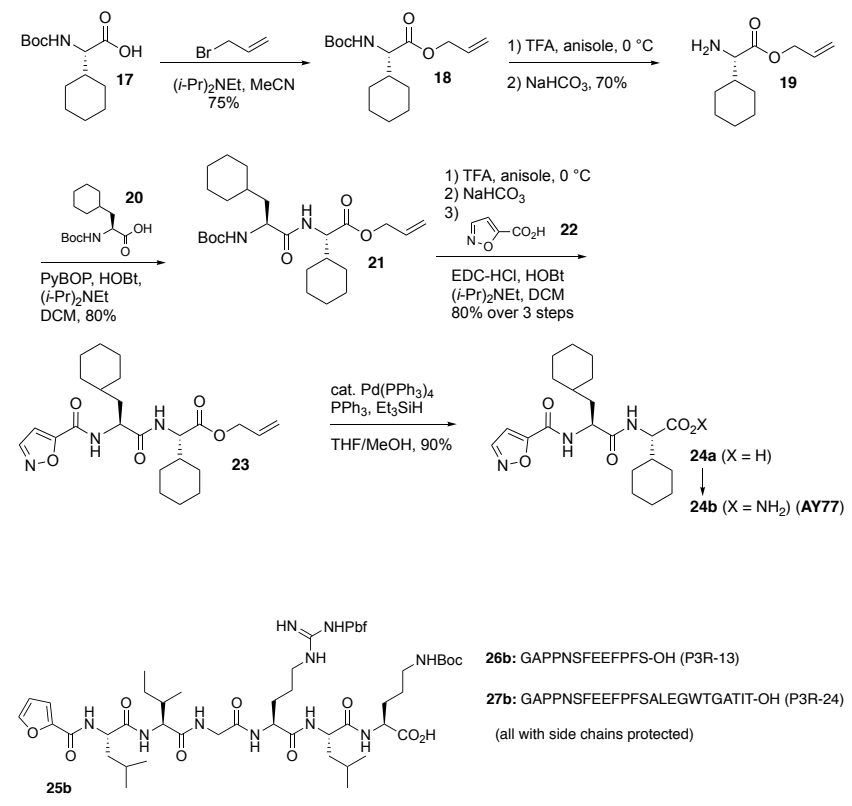

Figure 4. PAR2 peptide agonists synthesized via SPPS. All side chains were kept protected prior to conjugation steps. 
Longer PAR2 agonist peptides were prepared via SPPS analogously to $\mathbf{5}$, using chlorotrityl resin, automated microwave reactor, and cleaving the peptides from the resin with protected side chains intact (Figure 4). In this manner, the protected and C-terminal acid version (25b) of the potent and widely used PAR2 agonist hexapeptide reported by McGuire (termed 2-furoyl-LIGRLO-NH${ }_{2}$ ) was synthesized. ${ }^{54}$ Finally, the protected 13-mer 26 (termed P3R-13) and 24-mer 27 (termed P3R-24) were synthesized, which correspond to the $\mathrm{N}$-terminal 13 and 24 residue tethered peptides of aPC-cleaved PAR3. These peptides were reported by Mosnier to promote barrier protection in endothelium, ${ }^{55}$ and prior work from Hansen and coworkers suggested that related PAR3 tethered ligands could activate either PAR1 or PAR2 in Jurkat T-cells. ${ }^{56}$

\section{Scheme 4. Assembly of heterobivalent ligands featuring cilengitide and AY77}

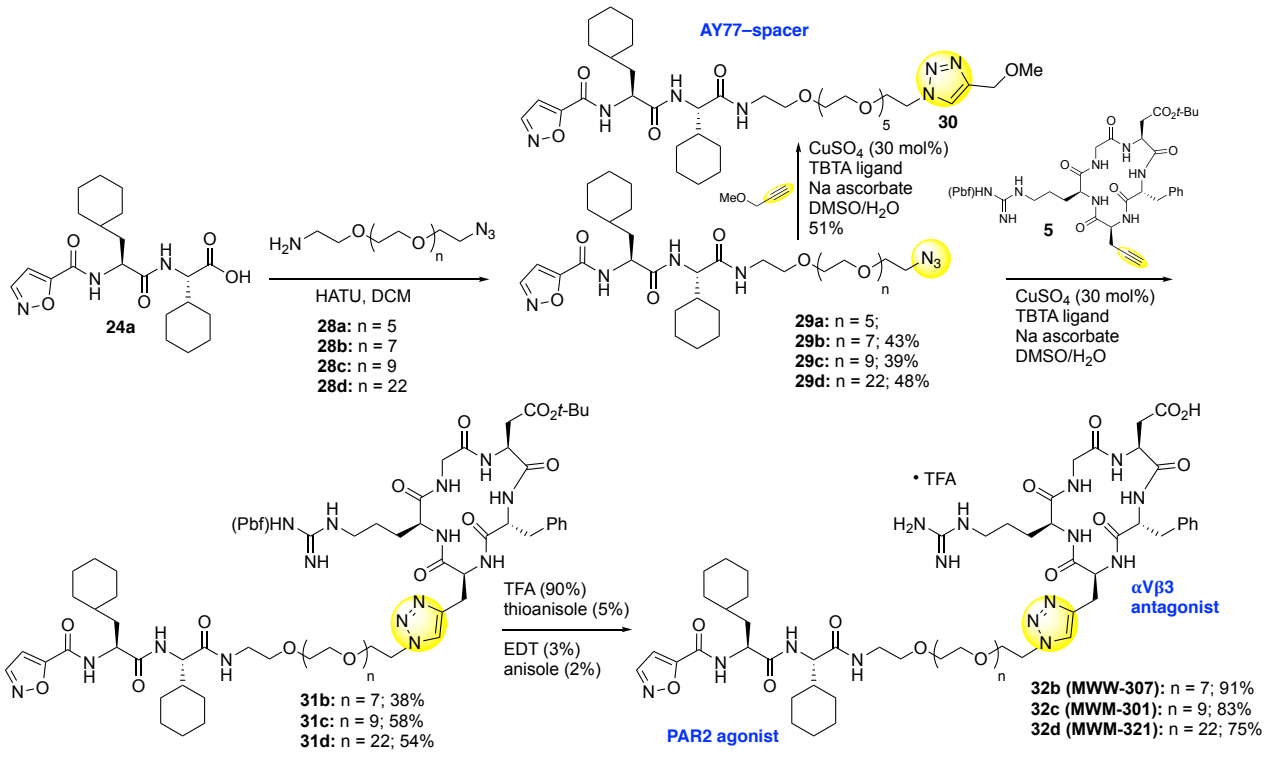

Scheme 5. Assembly of heterobivalent ligands featuring cilengitide and 2-furoyl-LIGRLO-NH

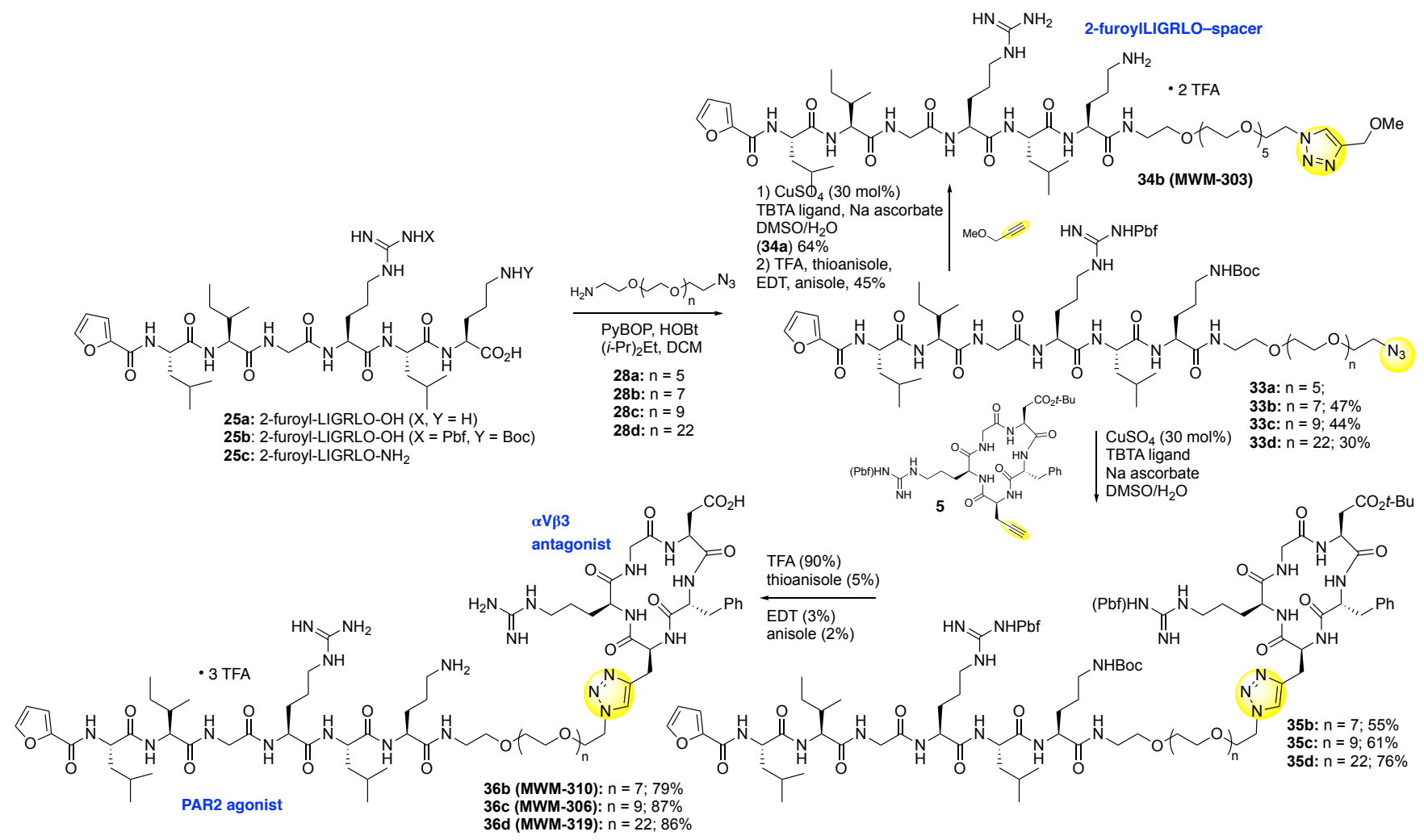




\section{Assembly of Bivalent Ligands}

Synthesis of the bivalent ligands and their respective monovalent spacer-linked controls proceeded according to the protocols outlined in Schemes 4 to 6. The carboxylic acid (24a) corresponding to AY77 (24b) was coupled using HATU to commercially available amino-PEG-azide spacers (28a-d) of four different lengths (termed informally as short, medium, long, and extra-long). The resulting amides $29 \mathbf{a}-\mathbf{d}$ were subjected to $\mathrm{CuAAC}$ reaction the protected alkynyl-cilengitide $\mathbf{5}$, generating the triazoles $\mathbf{3 1 b}-\mathbf{d}$, respectively. Improved results were obtained when using the ligand TBTA reported by Fokin. ${ }^{57}$ Global deprotection with a cocktail of TFA and carbocation scavengers generated the bivalent ligands $\mathbf{3 1 b}-\mathbf{d}$. Alternatively, the azide 29a was subjected to CuAAC with methyl propargyl ether to generate the control compound 30, composed of the PAR2 agonist with a triazole-capped spacer. All final compounds and intermediates in Schemes 4 to 6 were purified via preparative HPLC.

In a similar fashion, the protected McGuire peptide $\mathbf{2 5 b}$ was used to generate cilengitide-conjugated bivalent ligands $\mathbf{3 6} \mathbf{b}-$ d, as well as the spacer-linked control compound $\mathbf{3 4 b}$ (Scheme 5). We were unsuccessful in generating in pure form several bivalent ligands derived from the longer peptides P3R13 (26) and P3R24 (27), as the protected versions of these suffered from extremely low solubility after coupling reactions, and the products were not successfully isolated after normal- or reverse-phase chromatography.

Finally, the alkynylated analog of Kessler's peptidomimetic (16) was subjected to CuAAC with several PAR2 agonists, including AY77 (Scheme 6). Compound 37a is the first bivalent ligand we prepared using 16, with our early pharmacology data reported here.

Scheme 6. Assembly of heterobivalent ligands featuring Kessler's ligand and AY77

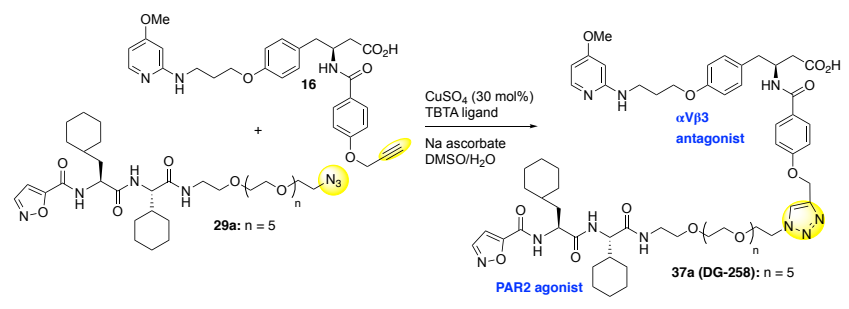

\section{Integrin Binding Assays}

To confirm that our modifications to the integrin ligands were well tolerated, we performed two preliminary binding assays. First, the binding of Alexa Fluor 647-labeled fibronectin to HEK293FT cells transfected with $\alpha \mathrm{V} \beta 3$ was measured in the presence of several bivalent ligands (Figure 5A). Cells expressing $\alpha \mathrm{V} \beta 3$ were also treated with an antibody to $\beta 3$ integrin (AlexFluor 488-labeled AP3), which was used to sort cells via flow cytometer, prior to fluorescence measurement. Both of the cilengitide-based bivalent ligands 32d (MWM321) and 36d (MWM-319) substantially inhibited fibronectin binding at a concentration of $5 \mu \mathrm{M}$, at a similar level to the established integrin binder cilengitide (cRGD). Though concentration-response curves have not yet been generated, these early results confirm that the attachment of the spacer to cilengitide does not appear to adversely impact its binding to $\alpha \mathrm{V} \beta 3$. Since our focus is on endothelial cells, we repeated this experiment with vitronectin coated plates and HUVEC, since
HUVEC also express fibronectin-binding $\alpha 5 \beta 1$. Cell binding was strongly inhibited by 32d, 36d, and 37a (DG-258).

\section{Calcium Mobilization Assays}

Next, we studied the ability of our bivalent ligands to activate PAR2 by measuring Gq-driven calcium mobilization in adherent endothelial cells, according to our reported plate reader protocol using Fluo-4/AM calcium sensing dye. ${ }^{58}$ All curves were fitted using data from $n \geq 3$ measurements on a single 96 well plate, with the error bars indicating the standard error of the mean (SEM). The cilengitide-AY77-based compounds from Scheme 4 were studied first in EA.hy926 cells (Figure 6). The control compound composed of AY77 with attached PEG spacer (30) had only moderately decreased potency $\left(\mathrm{EC}_{50}=0.89 \mu \mathrm{M}\right)$ relative to $\mathrm{AY} 77\left(\mathbf{2 4 b}, \mathrm{EC}_{50}=0.27\right.$ $\mu \mathrm{M})$, with similar efficacy. The bivalent ligand with the medium length spacer (32b) provided the best results with comparable potency to $\mathrm{AY} 77\left(\mathrm{EC}_{50}=0.56 \mu \mathrm{M}\right)$, with significantly increased efficacy. The bivalent ligand with the long $\left(\mathrm{EC}_{50}=\right.$ $0.88 \mu \mathrm{M})$ and extra-long $\left(\mathrm{EC}_{50}=2.5 \mu \mathrm{M}\right)$ spacers possessed lower potencies in this assay.

A

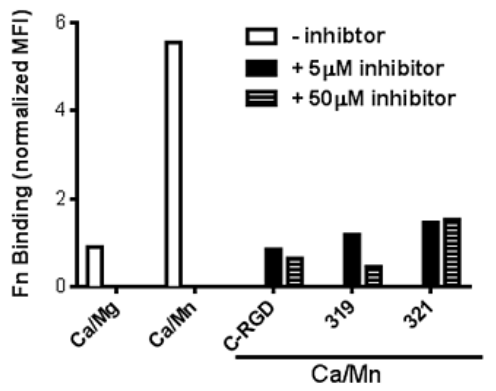

B
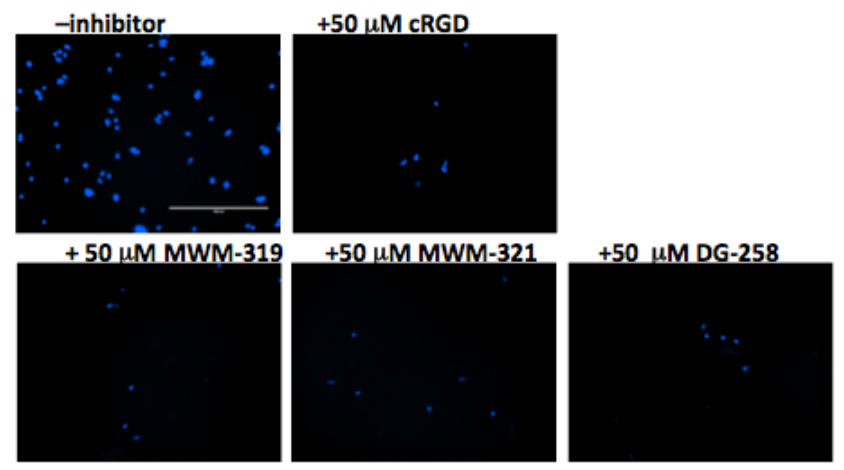

Figure 5. A) Inhibition of AlexaFluor 647-labeled fibronectin binding to $\alpha \mathrm{V} \beta 3$-containing HEK293 cells was measured in the presence of the bivalent ligands cilengitide (cRGD), 33d (MWM321) and 36d (MWM-319). Added calcium (0.2 mM) and manganese $(2 \mathrm{mM})$ are required for cell binding to fibronectin (2nd column). B). Binding of HUVEC (stained with DAPI, $5 \mu \mathrm{g} / \mathrm{mL}$ ) to vitronectin-coated plates, and inhibition of binding by $50 \mu \mathrm{M}$ cRGD, MWM-319, MWM-321, and DG-258. See Supporting Info for details.

Concentration-response curves generated with the bivalent ligands containing the McGuire peptide (2-furoyl-LIGRLO$\mathrm{NH}_{2}$ ) are shown in Figure 7. Interestingly, all of the spacerlinked agonists were more potent than the parent compound 25c $\left(\mathrm{EC}_{50}=0.35 \mu \mathrm{M}\right)$. The potencies were similar for the spacer-linked control 34b $\left(\mathrm{EC}_{50}=0.073 \mu \mathrm{M}\right)$ and the medium, 
long, and extra-long bivalent ligands 36b, 36c, and 36d $\left(\mathrm{EC}_{50}\right.$ $=0.062,0.084$, and $0.13 \mu \mathrm{M}$, respectively). Again, the bivalent ligand with the medium length PEG spacer (28 atoms, including one nitrogen at each end) was optimal.

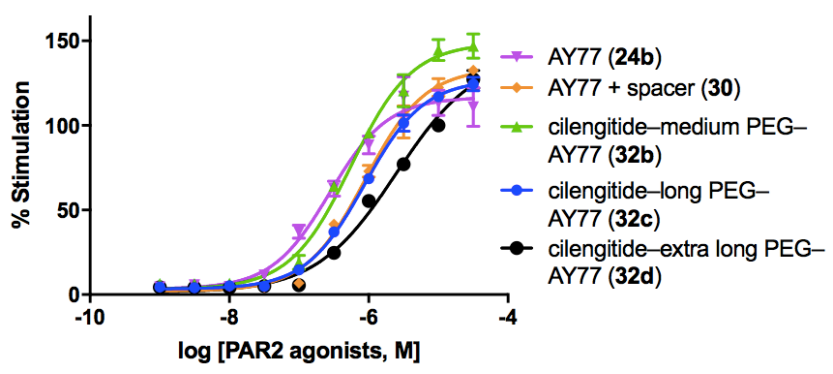

Figure 6. Stimulation of calcium mobilization in EA.hy926 cells by cilengitide-AY77 PAR2 agonists. Error bars indicate SEM ( $\geq 3$ ).

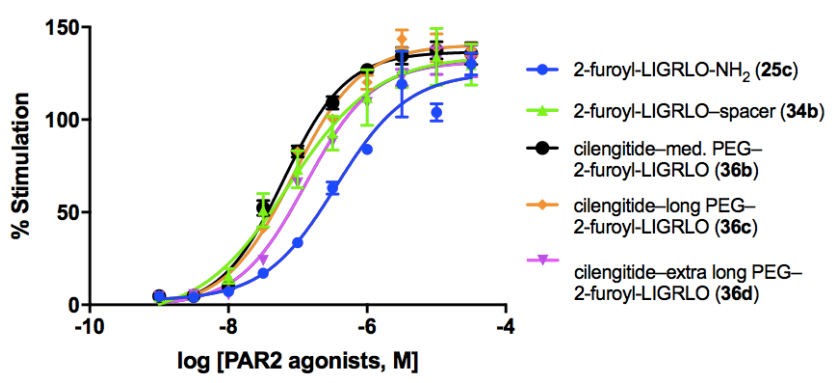

Figure 7. Stimulation of calcium mobilization in EA.hy926 cells by cilengitide-McGuire peptide PAR2 agonists. Error bars indicate SEM $(n \geq 3)$

Several bivalent ligands were also tested in cultured human umbilical vein endothelial cells (HUVEC) (Figure 8). The results were very similar compared to the EA.hy926 cells, with the ligand derived from the McGuire peptide $\left(36 \mathbf{c}, \mathrm{EC}_{50}=\right.$ $0.09 \mu \mathrm{M})$ approximately 10 -fold more potent than the analogous ligand with AY77 $\left(\mathbf{3 2 c}, \mathrm{EC}_{50}=1.0 \mu \mathrm{M}\right)$.

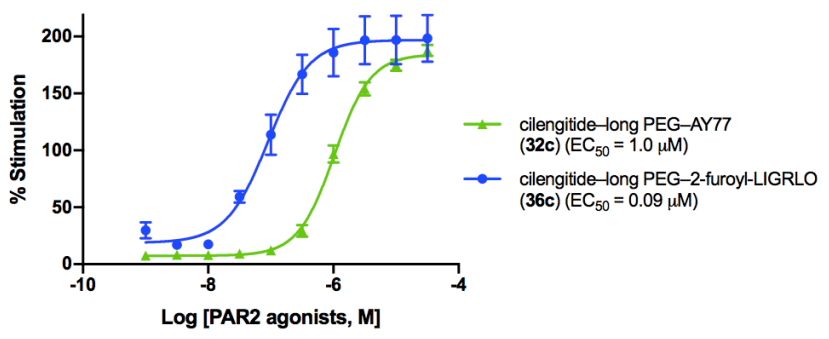

Figure 8. Stimulation of calcium mobilization in HUVEC by bivalent PAR2 agonists 32c and 36c.

We did not observe any significant increase in potency for the bivalent ligands over the monovalent controls, which would support the existence of $\alpha \mathrm{V} \beta 3$-PAR2 complexes, or at least the two receptors residing within the span of the longest bivalent ligands (possessing 72 atom spacers). Nonetheless, we performed competition studies to test for bivalency by adding a competing monovalent ligand. If a bivalent ligand shows increased binding and activity due to concurrent interactions with two receptors (e.g. within a heteromeric complex), we would expect binding and activity to decrease upon addition of a competing monovalent ligand. In our studies, the activities of our bivalent ligands at PAR2 were measured (via calcium mobilization) in the presence of the $\alpha \mathrm{V} \beta 3$ ligand cilengitide (Figure 9). No decrease in potency of the bivalent ligand 32d (composed of cilengitide and AY77, joined by the extra-long PEG spacer) was observed in EA.hy926 cells upon addition of $10 \mu \mathrm{M}$ cilengitide, although a decrease in efficacy was observed at the highest concentrations.

We reasoned that putative integrin-PAR complexes may only emerge under conditions of cellular stress, and evidence suggests that PAR2 plays an important role in the inflammatory responses to lipopolysaccharide (LPS), ${ }^{59}$ the bacterial cell membrane component. ${ }^{60}$ Concentration-response curves with EA.hy926 cells were measured with 32d after a $2 \mathrm{~h}$ pretreatment with $10 \mu \mathrm{g} / \mathrm{mL}$ LPS. No significant differences in potency were noted, with or without the addition of cilengitide (Figure 9). Similar results were obtained with the bivalent ligand derived from the McGuire peptide (36d, Figure S1).

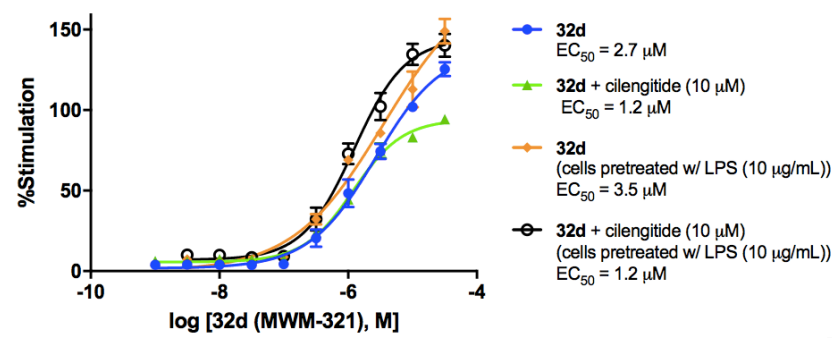

Figure 9. Stimulation of calcium mobilization in EA.hy926 cells pretreated with LPS by bivalent PAR2 agonist 32d (MWM-321), with and without cilengitide as a competing ligand. Cells were pretreated with $10 \mu \mathrm{g} / \mathrm{mL}$ LPS for $2 \mathrm{~h}$ prior to addition of ligand(s).

We also did not observe evidence of bivalency or improved potency after pretreatment with LPS using the bivalent ligand derived from Kessler's peptidomimetic $\alpha \mathrm{V} \beta 3$ inhibitor and the PAR2 agonist AY77 (37a, DG-258). In these cases, there was no statistical difference in potency $\left(\mathrm{EC}_{50}=1.2 \mu \mathrm{M}\right.$ for $37 \mathrm{a}$ alone) with or without the addition of $10 \mu \mathrm{M}$ cilengitide, and with or without pretreatment for $2 \mathrm{~h}$ with $10 \mu \mathrm{g} / \mathrm{mL}$ LPS (Figure S2).

\section{CONCLUSIONS}

We have reported a toolbox of bifunctional molecules designed to target both integrins and PARs. Consistent with the results of Kiessling ${ }^{35}$ and others, known $\alpha \mathrm{V} \beta 3$ ligands could be modified with the attachment of spacers without precluding integrin binding. Similarly, inspired by the prior results of Boitano, ${ }^{45}$ PAR2 agonists could be successfully modified by attachment of spacers without decreases in potency for the activation of calcium mobilization in endothelial cells. In preliminary experiments, we did not observe obvious changes in concentration-responses that would be diagnostic of the presence of a population of putative $\alpha \mathrm{V} \beta 3-\mathrm{PAR} 2$ complexes that could be selectively activated by our bivalent ligands. However, investigations in cellular models of inflammation are pending with these and related bivalent ligands in various cell types, which have the potential to characterize and modify signaling unique to specific cell surface receptor complexes that may have diagnostic and therapeutic applications in the future. 


\section{ASSOCIATED CONTENT}

\section{Supporting Information}

Additional assay data (Figures S1-S2); assay protocols; synthetic protocols; compound characterization data $\left({ }^{1} \mathrm{H}\right.$ NMR, ${ }^{13} \mathrm{C}$ NMR, and LC-MS traces) (PDF).

\section{AUTHOR INFORMATION}

\section{Corresponding Author}

* Email: christopher.dockendorff@mu.edu Tel: 1-414-288-1617.

\section{Author Contributions}

Conceived the project: C.D., H.W. Designed compounds: C.D. Designed synthetic routes: C.D., M.W.M., D.M.G. Synthesized and characterized compounds: M.W.M., D.M.G., T.H., R.R. Cultured cells: I.H., M.W.M., D.G., R.R. Performed assays: M.W.M., R.R., S.S., Z.W. Analyzed data: M.W.M., C.D., Z.W., J.Z., H.W. Wrote the manuscript: M.W.M., C.D. Prepared Supporting Information: M.W.M., D.M.G., R.R., C.D., Z.W., J.Z.

\section{Funding Sources}

C.D. thanks the National Heart, Lung, and Blood Institute (NHLBI) (R15HL127636); C.D. and R.R. thank Marquette University for a Summer Faculty Fellowship and Regular Research Grant; C.D. and H.W. thank the Clinical and Translational Science Institute of Southeast Wisconsin (8UL1TR000055); H.W. thanks NHLBI (R01HL133348); and J.Z. thanks NHLBI (R01HL131836) for support of the work described here.

\section{Notes}

A preliminary version of this manuscript was submitted to the preprint server ChemRxiv.

\section{ACKNOWLEDGMENT}

We thank Prof. Nicolas Moitessier for providing the FITTED ${ }^{\circledR}$ software used for docking studies and Dr. Sheng Cai (Marquette University) for assistance with LC-MS and NMR instruments. We thank ACD/Labs (NMR processing) and ChemAxon (NMR prediction and compound property prediction) for software. We thank the Nowick lab (UC-Irvine) for sharing detailed protocols for solid-phase peptide synthesis.

\section{ABBREVIATIONS}

Boc, tert-butoxycarbonyl; cRGD, cilengitide; COMU, (1-cyano2-ethoxy-2-oxoethylidenaminooxy)dimethylamino-morpholinocarbenium hexafluorophosphate; CuAAc, copper-catalyzed alkyne/azide cycloadditions; DAPI, 4',6-diamidino-2-phenylindole; DCE, 1,2-dichloroethane; DCM, dichloromethane; DIEA, $\mathrm{N}, \mathrm{N}$ diisopropylethylamine; DMAP, 4-dimethylaminopyridine; DPPF, 1,1'-bis(diphenylphosphino)ferrocene; EDC, 1-ethyl-3-(3dimethylaminopropyl)carbodiimide; FDA, U.S. Food and Drug Administration; GPCR, G-protein coupled receptor; Fmoc, Fluorenylmethyloxycarbonyl; HATU, hexafluorophosphate azabenzotriazole tetramethyl uronium; $\mathrm{HOBt}$, 1hydroxybenzotriazole; HUVEC, human umbilical vein endothelial cells; $\mathrm{IC}_{50}$, half-maximal inhibitory concentration; $i \mathrm{Ca}^{2+}$, intracellular calcium mobilization; MIDAS, metal ion-dependent adhesion site; PAR, Protease-activated receptor; Pbf, 2,2,4,6,7pentamethyldihydrobenzofuran-5-sulfonyl; PyBOP, (benzotriazol1-yloxy)tripyrrolidinophosphonium hexafluorophosphate; SEM, standard error of the mean; TBTA, tris(benzyltriazolylmethyl)amine.

\section{REFERENCES}

(1) Adams, M. N., Ramachandran, R., Yau, M.-K., Suen, J. Y., Fairlie, D. P., Hollenberg, M. D., and Hooper, J. D. (2011) Structure, function and pathophysiology of protease activated receptors. Pharmacol. Ther. 130, 248-282.

(2) Rothmeier, A. S., and Ruf, W. (2012) Protease-activated receptor 2 signaling in inflammation. Semin Immunopathol 34, 133-149.

(3) Yau, M.-K., Liu, L., and Fairlie, D. P. (2013) Toward drugs for protease-activated receptor 2 (PAR2). J. Med. Chem. 56, 74777497.

(4) Kanke, T., Kabeya, M., Kubo, S., Kondo, S., Yasuoka, K., Tagashira, J., Ishiwata, H., Saka, M., Furuyama, T., Nishiyama, T., Doi, T., Hattori, Y., Kawabata, A., Cunningham, M. R., and Plevin, R. (2009) Novel antagonists for proteinase-activated receptor 2: inhibition of cellular and vascular responses in vitroand in vivo. British Journal of Pharmacology 158, 361-371.

(5) Lohman, R. J., Cotterell, A. J., Suen, J., Liu, L., Do, A. T., Vesey, D. A., and Fairlie, D. P. (2012) Antagonism of Protease-Activated Receptor 2 Protects against Experimental Colitis. Journal of Pharmacology and Experimental Therapeutics 340, 256-265.

(6) Suen, J. Y., Barry, G. D., Lohman, R. J., Halili, M. A., Cotterell, A. J., Le, G. T., and Fairlie, D. P. (2012) Modulating human proteinase activated receptor 2 with a novel antagonist (GB88) and agonist (GB110). British Journal of Pharmacology 165, 1413-1423.

(7) Jiang, Y., Yau, M.-K., Lim, J., Wu, K.-C., Xu, W., Suen, J. Y., and Fairlie, D. P. (2018) A Potent Antagonist of Protease-Activated Receptor 2 That Inhibits Multiple Signaling Functions in Human Cancer Cells. Journal of Pharmacology and Experimental Therapeutics 364, 246-257.

(8) Ramachandran, R., Mihara, K., Mathur, M., Rochdi, M. D., Bouvier, M., DeFea, K., and Hollenberg, M. D. (2009) Agonist-Biased Signaling via Proteinase Activated Receptor-2: Differential Activation of Calcium and Mitogen-Activated Protein Kinase Pathways. Molecular Pharmacology 76, 791-801.

(9) Suen, J. Y., Cotterell, A., Lohman, R. J., Lim, J., Han, A., Yau, M. K., Liu, L., Cooper, M. A., Vesey, D. A., and Fairlie, D. P. (2014) Pathway-selective antagonism of proteinase activated receptor 2 . British Journal of Pharmacology 171, 4112-4124.

(10) Jiang, Y., Yau, M.-K., Kok, W. M., Lim, J., Wu, K.-C., Liu, L., Hill, T. A., Suen, J. Y., and Fairlie, D. P. (2017) Biased Signaling by Agonists of Protease Activated Receptor 2. ACS Chem. Biol. 12, 1217-1226.

(11) Zhao, P., Metcalf, M., and Bunnett, N. W. (2014) Biased signaling of protease-activated receptors. Front Endocrinol (Lausanne) 5, 67.

(12) Rajagopal, S., Rajagopal, K., and Lefkowitz, R. J. (2010) Teaching old receptors new tricks: biasing seven-transmembrane receptors. Nat Rev Drug Discov 9, 373-386.

(13) Rankovic, Z., Brust, T. F., and Bohn, L. M. (2016) Biased agonism: An emerging paradigm in GPCR drug discovery. Bioorg. Med. Chem. Lett. 26, 241-250.

(14) Tan, L., Yan, W., McCorvy, J. D., and Cheng, J. (2018) Biased Ligands of $G$ Protein-Coupled Receptors (GPCRs): StructureFunctional Selectivity Relationships (SFSRs) and Therapeutic Potential. J. Med. Chem. 61, 9841-9878.

(15) Kenakin, T. (2019) Biased Receptor Signaling in Drug Discovery. Pharmacological Reviews (Barker, E. L., Ed.) 71, 267-315.

(16) Lin, H., Liu, A. P., Smith, T. H., and Trejo, J. (2013) Cofactoring and Dimerization of Proteinase-Activated Receptors. Pharmacological Reviews 65, 1198-1213.

(17) Gieseler, F., Ungefroren, H., Settmacher, U., Hollenberg, M. D., and Kaufmann, R. (2013) Proteinase-activated receptors (PARs) focus on receptor-receptor-interactions and their physiological and pathophysiological impact. Cell Commun. Signal 11, 86.

(18) Disse, J., Petersen, H. H., Larsen, K. S., Persson, E., Esmon, N., Esmon, C. T., Teyton, L., Petersen, L. C., and Ruf, W. (2011) The Endothelial Protein C Receptor Supports Tissue Factor Ternary Coagulation Initiation Complex Signaling through Protease-activated Receptors. Journal of Biological Chemistry 286, 5756-5767. 
(19) Kaneider, N. C., Leger, A. J., Agarwal, A., Nguyen, N., Perides, G., Derian, C., Covic, L., and Kuliopulos, A. (2007) "Role reversal" for the receptor PAR1 in sepsis-induced vascular damage. Nat Immunol 8, 1303-1312.

(20) Portoghese, P. S. (2001) From Models to Molecules: Opioid Receptor Dimers, Bivalent Ligands, and Selective Opioid Receptor Probes. J. Med. Chem. 44, 2259-2269.

(21) Shonberg, J., Scammells, P. J., and Capuano, B. (2011) Design Strategies for Bivalent Ligands Targeting GPCRs. ChemMedChem 6, 963-974.

(22) Hiller, C., Kühhorn, J., and Gmeiner, P. (2013) Class A GProtein-Coupled Receptor (GPCR) Dimers and Bivalent Ligands. J. Med. Chem. 56, 6542-6559.

(23) Majewski, M. W., Gandhi, D. M., Rosas, R., Kodali, R., Arnold, L. A., and Dockendorff, C. (2019) Design and Evaluation of Heterobivalent PAR1-PAR2 Ligands as Antagonists of Calcium Mobilization. ACS Med Chem Lett 10, 121-126.

(24) Griffin, J. H., Fernandez, J. A., Gale, A. J., and Mosnier, L. O. (2007) Activated protein C. J. Thromb. Haemost. 5 Supp/ 1, 7380.

(25) Ranieri, V. M., Thompson, B. T., Barie, P. S., Dhainaut, J.-F., Douglas, I. S., Finfer, S., Gårdlund, B., Marshall, J. C., Rhodes, A., Artigas, A., Payen, D., Tenhunen, J., Al-Khalidi, H. R., Thompson, V., Janes, J., Macias, W. L., Vangerow, B., and Williams, M. D. (2012) Drotrecogin Alfa (Activated) in Adults with Septic Shock. $N$ Engl J Med 366, 2055-2064.

(26) Xiong, J.-P., Stehle, T., Zhang, R., Joachimiak, A., Frech, M., Goodman, S. L., and Arnaout, M. A. (2002) Crystal structure of the extracellular segment of integrin $\alpha \mathrm{V} \beta 3$ in complex with an Arg-GlyAsp ligand. Science 296, 151-155.

(27) Cox, D., Brennan, M., and Moran, N. (2010) Integrins as therapeutic targets: lessons and opportunities. Nat Rev Drug Discov 9 , 804-820.

(28) Estevez, B., Shen, B., and Du, X. (2015) Targeting integrin and integrin signaling in treating thrombosis. Arteriosclerosis, Thrombosis, and Vascular Biology 35, 24-29.

(29) Ley, K., Rivera-Nieves, J., Sandborn, W. J., and Shattil, S (2016) Integrin-based therapeutics: biological basis, clinical use and new drugs. Nat Rev Drug Discov 15, 173-183.

(30) Schottelius, M., Laufer, B., Kessler, H., and Wester, H.-J. (2009) Ligands for mapping alphavbeta3-integrin expression in vivo. Acc. Chem. Res. 42, 969-980.

(31) Dechantsreiter, M. A., Planker, E., Mathä, B., Lohof, E., Hölzemann, G., Jonczyk, A., Goodman, S. L., and Kessler, H. (1999) NMethylated Cyclic RGD Peptides as Highly Active and Selective aVß3 Integrin Antagonists. J. Med. Chem. 42, 3033-3040.

(32) Mas-Moruno, C., Rechenmacher, F., and Kessler, H. (2010) Cilengitide: the first anti-angiogenic small molecule drug candidate. Design, synthesis and clinical evaluation. Anticancer Agents Med Chem 10, 753-768

(33) Neubauer, S., Rechenmacher, F., Brimioulle, R., Di Leva, F. S., Bochen, A., Sobahi, T. R., Schottelius, M., Novellino, E., MasMoruno, C., Marinelli, L., and Kessler, H. (2014) Pharmacophoric Modifications Lead to Superpotent $\alpha v \beta 3$ Integrin Ligands with Suppressed $\alpha 5 \beta 1$ Activity. J. Med. Chem. 57, 3410-3417.

(34) Corbeil, C. R., Englebienne, P., and Moitessier, N. (2007) Docking ligands into flexible and solvated macromolecules. 1. Development and validation of FITTED 1.0. Journal of Chemical Information and Modeling 47, 435-449.

(35) Carlson, C. B., Mowery, P., Owen, R. M., Dykhuizen, E. C., and Kiessling, L. L. (2007) Selective tumor cell targeting using lowaffinity, multivalent interactions. ACS Chem. Biol. 2, 119-127.

(36) Haubner, R., Kuhnast, B., Mang, C., Weber, W. A., Kessler, H., Wester, H.-J., and Schwaiger, M. (2004) [ 18F]Galacto-RGD: Synthesis, Radiolabeling, Metabolic Stability, and Radiation Dose Estimates. Bioconjugate Chem. 15, 61-69.

(37) Shi, J., Wang, L., Kim, Y.-S., Zhai, S., Liu, Z., Chen, X., and Liu, S. (2008) Improving Tumor Uptake and Excretion Kinetics of 99mTc-Labeled Cyclic Arginine-Glycine-Aspartic (RGD) Dimers with Triglycine Linkers. J. Med. Chem. 51, 7980-7990.
(38) Gavrilyuk, J. I., Wuellner, U., Salahuddin, S., Goswami, R. K., Sinha, S. C., and Barbas, C. F. (2009) An efficient chemical approach to bispecific antibodies and antibodies of high valency. Bioorg. Med. Chem. Lett. 19, 3716-3720.

(39) Liu, S. (2009) Radiolabeled Cyclic RGD Peptides as Integrin $\alpha$ v $\beta$ 3-Targeted Radiotracers: Maximizing Binding Affinity via Bivalency. Bioconjugate Chem. 20, 2199-2213.

(40) Xiao, W., Wang, Y., Lau, E. Y., Luo, J., Yao, N., Shi, C., Meza, L., Tseng, H., Maeda, Y., Kumaresan, P., Liu, R., Lightstone, F. C., Takada, Y., and Lam, K. S. (2010) The Use of One-Bead OneCompound Combinatorial Library Technology to Discover HighAffinity v 3 Integrin and Cancer Targeting Arginine-GlycineAspartic Acid Ligands with a Built-in Handle. Molecular Cancer Therapeutics 9, 2714-2723.

(41) Rechenmacher, F., Neubauer, S., Polleux, J., Mas-Moruno, C., De Simone, M., Cavalcanti-Adam, E. A., Spatz, J. P., Fässler, R., and Kessler, H. (2012) Functionalizing $\alpha v \beta 3$ - or $\alpha 5 \beta 1$-Selective Integrin Antagonists for Surface Coating: A Method To Discriminate Integrin Subtypes In Vitro. Angew. Chem. Int. Ed. 52, 1572-1575.

(42) Zheng, Y., Ji, S., Czerwinski, A., Valenzuela, F., Pennington, M., and Liu, S. (2014) FITC-conjugated cyclic RGD peptides as fluorescent probes for staining integrin $\alpha v \beta 3 / \alpha v \beta 5$ in tumor tissues. Bioconjugate Chem. 25, 1925-1941.

(43) Shaw, S. K., Schreiber, C. L., Roland, F. M., Battles, P. M., Brennan, S. P., Padanilam, S. J., and Smith, B. D. (2018) High expression of integrin $\alpha \mathrm{v} \beta 3$ enables uptake of targeted fluorescent probes into ovarian cancer cells and tumors. Bioorganic \& Medicinal Chemistry 26, 2085-2091.

(44) Bolzati, C., Salvarese, N., Carpanese, D., Seraglia, R., MeléndezAlafort, L., Rosato, A., Capasso, D., Saviano, M., Del Gatto, A., Comegna, D., and Zaccaro, L. (2018) [ 99mTc][Tc(N)PNP43]Labeled RGD Peptides As New Probes for a Selective Detection of $\alpha v \beta$ 3Integrin: Synthesis, Structure-Activity and Pharmacokinetic Studies. J. Med. Chem. 61, 9596-9610.

(45) Flynn, A. N., Hoffman, J., Tillu, D. V., Sherwood, C. L., Zhang, Z., Patek, R., Asiedu, M. N. K., Vagner, J., Price, T. J., and Boitano, S. (2013) Development of highly potent protease-activated receptor 2 agonists via synthetic lipid tethering. The FASEB Journal 27, 14981510.

(46) Kennedy, A. J., Ballante, F., Johansson, J. R., Milligan, G., Sundström, L., Nordqvist, A., and Carlsson, J. (2018) Structural Characterization of Agonist Binding to Protease-Activated Receptor 2 through Mutagenesis and Computational Modeling. ACS Pharmacology \& Translational Science 1, 119-133.

(47) Cheng, R. K. Y., Fiez-Vandal, C., Schlenker, O., Edman, K., Aggeler, B., Brown, D. G., Brown, G. A., Cooke, R. M., Dumelin, C. E., Doré, A. S., Geschwindner, S., Grebner, C., Hermansson, N.-O., Jazayeri, A., Johansson, P., Leong, L., Prihandoko, R., Rappas, M., Soutter, H., Snijder, A., Sundström, L., Tehan, B., Thornton, P., Troast, D., Wiggin, G., Zhukov, A., Marshall, F. H., and Dekker, N. (2017) Structural insight into allosteric modulation of proteaseactivated receptor 2. Nature 545, 112-115.

(48) Tornøe, C. W., Christensen, C., and Meldal, M. (2002) Peptidotriazoles on Solid Phase: [1,2,3]-Triazoles by Regiospecific Copper(I)-Catalyzed 1,3-Dipolar Cycloadditions of Terminal Alkynes to Azides. J. Org. Chem. 67, 3057-3064.

(49) Rostovtsev, V. V., Green, L. G., Fokin, V. V., and Sharpless, K. B. (2002) A Stepwise Huisgen Cycloaddition Process: Copper(I)Catalyzed Regioselective "Ligation" of Azides and Terminal Alkynes. Angew. Chem. Int. Ed. 41, 2596-2599.

(50) Yamada, K., Nagashima, I., Hachisu, M., Matsuo, I., and Shimizu, H. (2012) Efficient solid-phase synthesis of cyclic RGD peptides under controlled microwave heating. Tetrahedron Letters 53, 1066 1070 .

(51) Carpino, L. A., Shroff, H., Triolo, S. A., Mansour, E.-S. M. E., Wenschuh, H., and Albericio, F. (1993) The 2,2,4,6,7pentamethyldihydrobenzofuran-5-sulfonyl group ( $\mathrm{Pbf}$ ) as arginine side chain protectant. Tetrahedron Letters 34, 7829-7832.

(52) Subiros-Funosas, R., Khattab, S. N., Nieto-Rodriguez, L., ElFaham, A., and Albericio, F. (2013) Advances in Acylation Method- 
ologies Enabled by Oxyma-Based Reagents. Aldrichimica Acta 46, $21-40$.

(53) Yau, M.-K., Suen, J. Y., Xu, W., Lim, J., Liu, L., Adams, M. N., He, Y., Hooper, J. D., Reid, R. C., and Fairlie, D. P. (2016) Potent Small Agonists of Protease Activated Receptor 2. ACS Med Chem Lett 7, 105-110.

(54) McGuire, J. J., Saifeddine, M., Triggle, C. R., Sun, K., and Hollenberg, M. D. (2004) 2-furoyl-LIGRLO-amide: a potent and selective proteinase-activated receptor 2 agonist. J. Pharmacol. Exp. Ther. 309, 1124-1131.

(55) Burnier, L., and Mosnier, L. O. (2013) Novel mechanisms for activated protein $\mathrm{C}$ cytoprotective activities involving noncanonical activation of protease-activated receptor 3. Blood 122, 807-816.

(56) Hansen, K. K., Saifeddine, M., and Hollenberg, M. D. (2004) Tethered ligand-derived peptides of proteinase-activated receptor 3 (PAR3) activate PAR1 and PAR2 in Jurkat T cells. Immunology 112, 183-190.
(57) Chan, T. R., Hilgraf, R., Sharpless, K. B., and Fokin, V. V. (2004) Polytriazoles as copper(I)-stabilizing ligands in catalysis. Org. Lett. 6, 2853-2855.

(58) Gandhi, D. M., Majewski, M. W., Rosas, R., Kentala, K., Foster, T. J., Greve, E., and Dockendorff, C. (2018) Characterization of Protease-Activated Receptor (PAR) ligands: Parmodulins are reversible allosteric inhibitors of PAR1-driven calcium mobilization in endothelial cells. Bioorganic \& Medicinal Chemistry 26, 2514-2529.

(59) Liang, H. P. H., Kerschen, E. J., Hernandez, I., Basu, S., Zogg, M., Botros, F., Jia, S., Hessner, M. J., Griffin, J. H., Ruf, W., and Weiler, H. (2015) EPCR-dependent PAR2 activation by the blood coagulation initiation complex regulates LPS-triggered interferon responses in mice. Blood 125, 2845-2854.

(60) Dauphinee, S. M., and Karsan, A. (2006) Lipopolysaccharide signaling in endothelial cells. Lab. Invest. 86, 9-22. 